\title{
Screening for Family and Intimate Partner Violence: Recommendation Statement
}

\section{U.S. Preventive Services Task Force}

Members of the U.S. Preventive Services Task Force* are Alfred O. Berg, MD, MPH, Chair, USPSTF (Professor and Chair, Department of Family Medicine, University of Washington, Seattle, Wasb); Janet D. Allan, PbD, RN, CS, Vice-chair, USPSTF (Dean, School of Nursing, University of Maryland Baltimore, Baltimore, Md), Paul Frame, MD (Tri-County Family Medicine, Cobocton, NY, and Clinical Professor of Family Medicine, University of Rochester, Rochester, NY); Charles J. Homer, MD, MPH (Executive Director, National Initiative for Children's Healthcare Quality, Boston, Mass), Mark S. Jobnson, MD, MPH (Professor of Family Medicine, University of Medicine and Dentistry of New Jersey-New Jersey Medical School, Newark, $N J)_{i}$ Jonathan D. Klein, MD, MPH (Associate Professor, Department of Pediatrics, University of Rochester School of Medicine, Rochester, NY); Tracy A. Lieu, MD, MPH (Associate Professor, Department of Ambulatory Care and Prevention, Harvard Pilgrim Health Care and Harvard Medical School, Boston, Mass); C. Tracy Orleans, PbD (Senior Scientist, The Robert Wood Jobnson Foundation, Princeton, NJ); Jeffrey F. Peipert, MD, MPH (Director of Research, Women and Infants' Hospital, Providence, RI); Nola J. Pender, $\mathrm{PbD}, \mathrm{RN}$ (Professor Emeritus, University of Michigan, Ann Arbor, Micb); Albert L. Siu, MD, MSPH (Professor of Medicine, Chief of Division of General Internal Medicine, Mount Sinai School of Medicine, New York, NY), Steven M. Teutsch, MD, MPH (Senior Director, Outcomes Research and Management, Merck \& Company, Inc., West Point, Pa); Carolyn Westhoff, MD, MSc (Professor of Obstetrics and Gynecology and Professor of Public Health, Columbia University, New York, NY); and Steven H. Woolf, MD, MPH (Professor, Department of Family Practice and Department of Preventive and Community Medicine and Director of Research Department of Family Practice, Virginia Commonwealth University, Fairfax, $\mathrm{Va}$ ).

\section{CORRESPONDING AUTHOR}

Alfred O. Berg, MD, MPH

Chair, U.S. Preventive Services Task Force c/o Project Director, USPSTF

Agency for Healthcare Research and Quality 540 Gaither Road

Rockville, MD 20850

uspstf@ahrq.gov

*Members of the Task Force at the time this recommendation was finalized. For a list of current Task Force members, go to http: //www.ahrq.gov/clinic/uspstfab.htm.
Ann Fam Med 2004;2:156-160. DOI: 10.1370/afm.128.

This statement summarizes the U.S. Preventive Services Task Force (USPSTF) recommendations on screening for family and intimate partner violence based on the USPSTF's examination of evidence specific to family and intimate partner violence. It updates the 1996 recommendations contained in the Guide to Clinical Preventive Services, second edition. ${ }^{1}$ In 1996, the USPSTF found insufficient evidence to recommend for or against the use of specific instruments to detect domestic violence (a " $\mathrm{C}^{\prime}$ recommendation according to 1996 grade definitions). The Task Force now uses an explicit process in which the balance of benefits and harms is determined exclusively by the quality and magnitude of the evidence. As a result, current letter grades are based on different criteria than those in 1996. Current explanations of the ratings and of the strength of overall evidence are given in Appendix A and in Appendix $B$, respectively. The complete information on which this statement is based, including evidence tables and references, is available in the summary article ${ }^{2,3}$ and in the Systematic Evidence Review, "Screening for Family and Intimate Partner Violence: Systematic Evidence Review for the U.S. Preventive Services Task Force." ${ }^{4}$ The USPSTF recommendations, the accompanying summary article, and complete Systematic Evidence Review are available through the USPSTF web site (http://www.preventiveservices.ahrq.gov). The summary article and the USPSTF recommendation statement are available in print through the AHRQ Publications Clearinghouse (call 1-800-358-9295 or e-mail ahrqpubs@ahrq.gov).

\section{SUMMARY OF RECOMMENDATION}

$\mathrm{T}$ he USPSTF found insufficient evidence to recommend for or against routine screening of parents or guardians for the physical abuse or neglect of children, of women for intimate partner violence, or of older adults or their caregivers for elder abuse. I recommendation.

The USPSTF found no direct evidence that screening for family and intimate partner violence leads to decreased disability or premature death. The USPSTF found no existing studies that determine the accuracy of screening tools for identifying family and intimate partner violence among children, women, or older adults in the general population. The USPSTF found fair to good evidence that interventions reduce barm to children when child abuse or neglect bas been assessed (see Clinical Considerations). The USPSTF found limited evidence as to whether interventions reduce barm to women, and no studies that examined the effectiveness of interventions in older adults. No studies bave directly addressed the barms of screening and interventions for family and intimate partner violence. As a result, the USPSTF could not determine the balance between the benefits and harms of screening for family and intimate partner violence among children, women, or older adults. 


\section{CLINICAL CONSIDERATIONS}

- The USPSTF did not review the evidence for the effectiveness of case-finding tools; however, all clinicians examining children and adults should be alert to physical and behavioral signs and symptoms associated with abuse or neglect. Patients in whom abuse is suspected should receive proper documentation of the incident and physical findings (eg, photographs, body maps), treatment for physical injuries; arrangements for skilled counseling by a mental health professional ${ }_{;}$and the telephone numbers of local crisis centers, shelters, and protective service agencies.

- Victims of family violence are primarily children, female spouses/intimate partners, and older adults. Numerous risk factors for family violence have been identified, although some may be confounded by socioeconomic factors. Factors associated with child abuse or neglect include low income status, low maternal education, non-white race, large family size, young maternal age, single-parent household, parental psychiatric disturbances, and presence of a stepfather. Factors associated with intimate partner violence include young age, low income status, pregnancy, mental health problems, alcohol or substance use by victims or perpetrators, separated or divorced status, and history of childhood sexual and/or physical abuse. Factors associated with the abuse of older adults include increasing age, non-white race, low income status, functional impairment, cognitive disability, substance use, poor emotional state, low self-esteem, cohabitation, and lack of social support.

- Several instruments to screen parents for child abuse have been studied, but their ability to predict child abuse or neglect is limited. Instruments to screen for intimate partner violence have also been developed, and although some have demonstrated good internal consistency (eg, the HITS instrument, the Partner Abuse Interview, and the Women's Experience with Battering [WEB] Scale), none have been validated against measurable outcomes. Only a few screening instruments (the Caregiver Abuse Screen [CASE] and the Hwalek-Sengstock Elder Brief Abuse Screen Test [HSEAST]) have been developed to identify potential older victims of abuse or their abusive caretakers. Both of these tools correlated well with previously validated instruments when administered in the community, but have not been tested in the primary care clinical setting. ${ }^{4}$

- Home visit programs directed at high-risk mothers (identified on the basis of sociodemographic risk factors) have improved developmental outcomes and decreased the incidence of child abuse and neglect, as well as decreased rates of maternal criminal activity and drug use.

\section{DISCUSSION}

Approximately 1 million abused children are identified in the U.S. each year. ${ }^{5}$ In 1999, an estimated 1,100 children died of abuse and neglect. ${ }^{6}$ It is likely that reported abuse captures only a fraction of all cases. Estimates of the prevalence of intimate partner violence in the U.S. indicate that 1 to 4 million women are physically, sexually, or emotionally abused by their intimate partners each year, ${ }_{1}^{7,8}$ with $31 \%$ of all women reporting abuse at some point in their lifetimes. ${ }^{9}$ Although violence by women against men also occurs, women are 7 to 14 times more likely to suffer severe physical injury from an assault by an intimate partner. ${ }^{10}$ The National Elder Abuse Incidence Study (NEAIS) estimates that approximately 551,000 older adults in domestic settings were abused and/or neglected during 1996. ${ }^{11}$ The abuse of older adults takes many forms, including physical, sexual, and psychological abuse; financial exploitation; and neglect. ${ }^{12}$ In $90 \%$ of cases, the perpetrator of such abuse is a family member, usually an adult child or spouse. ${ }^{11}$ Harmful outcomes of family violence may include not only repercussions of acute trauma, including death or unwanted pregnancy, but also long-term physical problems and psychiatric disorders such as depression, post-traumatic stress disorder, somatization, suicide, and substance abuse. ${ }^{13-23}$ In addition, children who witness intimate partner violence are at risk for developmental delay, school failure, violent behavior, and a variety of psychiatric disorders, including depression and oppositional defiant disorder. ${ }^{24-26}$

The USPSTF focused this review on children, women, and older adults because they are the largest groups at risk for domestic violence in the general primary care setting and are most likely to have been the subjects of published studies. The USPSTF reviewed the evidence for the effectiveness of screening procedures and interventions in the primary care setting in reducing harmful outcomes of domestic violence against children, women, and older adults. Because no studies were found that directly addressed the impact of screening on reducing harmful outcomes, the USPSTF examined the accuracy of clinical screening instruments in identifying risk for current or future abuse and the efficacy of clinic-based interventions in reducing harmful outcomes.

Screening for child abuse in the primary care setting can involve a variety of techniques, including physical examination as well as screening questionnaires. Findings during a routine physical examination suggestive of abuse and/or neglect, such as burns, bruises, and repeated suspicious traumatic injury, have been described.$^{27}$ All instruments designed to screen 
for child abuse and neglect were directed at parents, particularly pregnant mothers. Limited evidence suggests that these instruments had fairly high sensitivity but low specificity for identifying future child maltreatment when administered in the study populations, particularly when self-administered questionnaires were provided to pregnant mothers in a 2-step method such as the Hawaii Risk Indicators Screening Tool followed by the Kempe Family Stress Inventory. ${ }^{28,29}$ These questionnaires have not been widely tested in different populations. Newer brief instruments designed to identify women who are victims of intimate partner violence in primary care settings compare well with lengthier, previously-validated instruments. ${ }^{4}$ Studies indicate that self-administered questionnaires elicit more positive responses than interviewer-administered questionnaires in emergency department settings, ${ }^{30}$ but the opposite was true in a Planned Parenthood clinic. ${ }^{31}$ No studies have evaluated the performance of screening instruments using verified outcomes of reported intimate partner abuse although self-reported abuse may be a more accurately measured outcome than some verified outcomes (ie, police or social services reports). The USPSTF found few screening instruments for the detection of older adults who are the potential victims of abuse or their caretakers. None of the instruments available have been widely validated.

The USPSTF reviewed the evidence for the efficacy of interventions with children, women, and older adults in reducing harmful outcomes of family and intimate partner violence. The intervention trials identified "high-risk" women and children based on various inclusion criteria that have not been validated, including sociodemographic characteristics, maternal substance use, low infant birth weight, and homelessness. A randomized controlled trial with 15 years of follow-up indicated that nurse home visit programs (ie, the Nurse Family Partnership program) during the prenatal and 2-year postpartum periods for low-income, first-time mothers can improve the short-term and long-term outcomes of child abuse and neglect. ${ }^{32,33}$ When compared with the nonintervention group, the home visit group had improved outcomes, including decreased reports of child maltreatment, child injuries/toxic ingestions and emergency room visits, and maternal criminal activity and drug use. Several trials utilizing nurse home visits for varying lengths of time and with various program components for pregnant and postpartum mothers support these findings, although the outcomes in these studies were short-term measures of child abuse and related factors. ${ }^{4}$ There were 2 studies of interventions to decrease intimate partner violence in women; both studies, which only recruited pregnant women, showed a trend (not statistically significant) in women reporting decreased violence after brief counseling or outreach interventions. ${ }^{34,35}$ There are no studies of interventions initiated in the primary care setting with health outcomes for older children, women who are not pregnant, or older adults. Further research is required to identify screening tools that are valid in the general population and effective programs that decrease abuse outcomes and the health-related consequences of family and intimate partner violence.

No studies have directly addressed the harms of screening and intervention for family and intimate partner violence. False-positive tests, most common in lowrisk populations, may compromise the clinician-patient relationship. ${ }^{36}$ Additional possible harms of screening may include loss of contact with established support systems, psychological distress, and an escalation of abuse. ${ }^{37}$ However, none of these potential harms has been studied.

\section{RECOMMENDATIONS OF OTHER GROUPS}

The American Academy of Pediatrics (AAP) ${ }^{38}$ and the American Medical Association (AMA) ${ }^{39,40}$ recommend that physicians remain alert for the signs and symptoms of child physical abuse and child sexual abuse in the routine examination. The Canadian Task Force on Preventive Health Care (CTFPHC) recommends that screening procedures aimed at identifying individuals at risk for experiencing or committing child maltreatment should be excluded from the periodic health examination. ${ }^{41}$ However, the CTFPHC recommends a program of home visitation for disadvantaged families during the perinatal period through infancy to prevent child abuse and neglect. The Centers for Disease Control and Prevention Task Force on Community Preventive Services found that home visitation programs aimed at children with high risk for maltreatment (eg, single or young mothers, low-income households, families with low birth-weight infants) were effective in decreasing maltreatment episodes. ${ }^{42}$ The American College of Obstetricians and Gynecologists (ACOG) $)^{43}$ guidelines on domestic violence recommend that physicians routinely ask women direct, specific questions about abuse. The AMA encourages physicians to inquire routinely about their patients' domestic violence histories and refer those patients with violence-related problems for medical and/or community-based services. ${ }^{44}$ The CTFPHC concluded that there was insufficient evidence to recommend for or against routine screening for violence against women. ACOG and $\mathrm{AMA}^{45}$ recommend that physicians routinely ask elderly patients direct, specific 


\section{APPENDIX A}

U.S. Preventive Services Task Force Recommendations and Ratings

The Task Force grades its recommendations according to one of 5 classifications $(A, B, C, D, I)$ reflecting the strength of evidence and magnitude of net benefit (benefits minus harms):

A. The USPSTF strongly recommends that clinicians provide [the service] to eligible patients. The USPSTF found good evidence that [the service] improves important health outcomes and concludes that benefits substantially outweigh harms.

B. The USPSTF recommends that clinicians provide [this service] to eligible patients. The USPSTF found at least fair evidence that [the service] improves important health outcomes and concludes that benefits outweigh harms.

C. The USPSTF makes no recommendation for or against routine provision of [the service]. The USPSTF found at least fair evidence that [the service] can improve health outcomes but concludes that the balance of benefits and harms is too close to justify a general recommendation.

D. The USPSTF recommends against routinely providing [the service] to asymptomatic patients. The USPSTF found at least fair evidence that [the service] is ineffective or that harms outweigh benefits.

I. The USPSTF concludes that the evidence is insufficient to recommend for or against routinely providing [the service]. Evidence that the [service] is effective is lacking, of poor quality, or conflicting and the balance of benefits and harms cannot be determined.

\section{APPENDIX B}

U.S. Preventive Services Task Force Strength of Overall Evidence The USPSTF grades the quality of the overall evidence for a service on a 3-point scale (good, fair, poor):

\section{Good}

Evidence includes consistent results from well-designed, well-conducted studies in representative populations that directly assess effects on health outcomes.

Fair

Evidence is sufficient to determine effects on health outcomes, but the strength of the evidence is limited by the number, quality, or consistency of the individual studies, generalizability to routine practice, or indirect nature of the evidence on health outcomes.

Poor

Evidence is insufficient to assess the effects on health outcomes because of limited number or power of studies, important flaws in their design or conduct, gaps in the chain of evidence, or lack of information on important health outcomes.

questions about abuse. The CTFPHC determined that there was insufficient evidence to include or exclude case-finding for elder abuse as part of the periodic health examination, but recommended that physicians be alert for indicators of abuse and institute measures to prevent further abuse. ${ }^{46}$ The American Academy of Family Physicians (AAFP) notes that family physicians can provide early intervention in family violence through routine screening and the identification of abuse, and recommends that physicians be alert for the presence of family violence in virtually every patient encounter. ${ }^{47}$ Reporting child and elder abuse to protective services is mandatory in most states, and several states have laws requiring mandatory reporting of intimate partner violence. ${ }^{48,49}$
To read of post commentaries in response to this article, see it online at http://www.annfammed.org/cgi/content/full/2/2/156.

Key words: Domestic violence; child abuse; elder abuse; spouse abuse

Disclaimer: Recommendations made by the USPSTF are independent of the U.S. Government. They should not be construed as an official position of AHRQ or the U.S. Department of Health and Human Services.

\section{References}

1. U.S. Preventive Services Task Force. Guide to Clinical Preventive Services. 2nd ed. Alexandria, VA: International Medical Publishing; 1996.

2. Nelson H, Nygren P, Mclnerney Y, Klein J. Screening Women and Elderly Adults for Family and Intimate Partner Violence: A Review of the Evidence for the U.S. Preventive Services Task Force. Ann Intern Med. 2004;140:387-396.

3. Nelson H, Nygren P, Klein J. Screening Children for Family Violence: A Review of the Evidence for the U.S. Preventive Services Task Force. Ann Fam Med. 2004;2:161.

4. Nelson HD, Nygren P, Qazi Y. Screening for Family and Intimate Partner Violence. Systematic Evidence Review No. 28. Prepared by the Oregon Health \& Science Evidence-based Practice Center under Contract No. 290-97-0018. Rockville, MD: Agency for Healthcare Research and Quality. March 2004. Available at: http://www.ahrq/ gov/clinic/serfiles.htm.

5. Sedlak AJ, Broadhurst DD. Third National Incidence Study of Child Abuse and Neglect: Final Report. Washington, DC: U.S. Dept of Health and Human Services, National Center on Child Abuse and Neglect; 1996

6. Child Maltreatment 1999: Reports from the States to the National Child Abuse and Neglect Data System. Washington, DC: U.S. Department of Health and Human Services; 2001.

7. Violence by Intimates: Analysis of Data on Crimes by Current or Former Spouses, Boyfriends, and Girlfriends. U.S. Department of Justice; 1998.

8. The Commonwealth Fund, First Comprehensive National Health Survey of American Women. 1993.

9. The Commonwealth Fund, Health Concerns Across A Woman's Lifespan: The Commonwealth Fund 1998 Survey of Women's Health. 1999.

10. Muelleman RL, Lenaghan PA, Pakieser RA. Battered women: injury locations and types. Ann Emerg Med. 1996;28:486-492.

11. Tatara T, Kuzmeskus-Blumerman L, Duckhorn E, et al. The National Elder Abuse Incidence Study (NEAIS); Final Report. National Center on Elder Abuse at the American Public Human Services Association in Collaboration with Westat, Inc. for the Administration for Children and Families and The Administration on Aging in the U.S. Department of Health and Human Services, 1998.

12. Elder abuse and neglect. Council on Scientific Affairs. JAMA. $1987 ; 257: 966-971$.

13. Felitti VJ, Anda RF, Nordenberg D, et al. Relationship of childhood abuse and household dysfunction to many of the leading causes of death in adults. The Adverse Childhood Experiences (ACE) Study. Am J Prev Med. 1998;14:245-258.

14. Silverman JG, Raj A, Mucci LA, Hathaway JE. Dating violence against adolescent girls and associated substance use, unhealthy weight control, sexual risk behavior, pregnancy, and suicidality. JAMA. 2001;286:572-579.

15. Dube SR, Anda RF, Felitti VJ, Chapman DP, Williamson DF, Giles WH. Childhood abuse, household dysfunction, and the risk of attempted suicide throughout the life span: findings from the Adverse Childhood Experiences Study. JAMA. 2001;286:3089-3096. 
16. Anda RF, Chapman DP, Felitti VJ, et al. Adverse childhood experiences and risk of paternity in teen pregnancy. Obstet Gynecol. 2002;100: 37-45.

17. Diaz A, Simantov E, Rickert VI. Effect of abuse on health: results of a national survey. Arch Pediatr Adolesc Med. 2002;156:811-817.

18. Osofsky JD, Wewers S, Hann DM, Fick AC. Chronic community violence: what is happening to our children? Psychiatry. 1993;56:36-45.

19. Shakoor BH, Chalmers D. Co-victimization of African-American children who witness violence: effects on cognitive, emotional and behavioral development. J Natl Med Assoc. 1991;83:233-238.

20. Lansford JE, Dodge KA, Pettit GS, Bates JE, Crozier J, Kaplow J. A 12 year prospective study of the long-term effects of early child physical maltreatment on psychological, behavioral, and academic problems in adolescence. Arch Pediatr Adolesc Med. 2002;156:824-830.

21. Campbell JC, Lewandowski LA. Mental and physical health effects of intimate partner violence on women and children. Psychiatr Clin North Am. 1997; 20:353-374.

22. Campbell DW, Sharps PW, Gary FA, Campbell JC, Lopez LM. Intimate partner violence in African American women. Online J Issues Nurs. 2002;7:5.

23. Coker AL, Smith PH, Thompson MP, McKeown RE, Bethea L, Davis KE. Social support protects against the negative effects of partner violence on mental health. J Womens Health Gend Based Med. 2002;11:465-476.

24. Maxfield M, Widom C. The cycle of violence, revisited 6 years later. Arch Adolesc Med. 1996;50:390-395.

25. Garbarino J, Kostelny DN. What children can tell us about living in danger. Am Psychol. 1991;46:376-383.

26. Durant RH, Pendergrast RA, Cadenhead C. Exposure to violence and victimization and fighting behavior by black urban adolescents. J Adolesc Health. 1994;15:311-318.

27. Johnson CF. Inflicted injury versus accidental injury. Pediatr Clin North Am. 1990;37:791-814.

28. Korfmacher J. The Kempe Family Stress Inventory: a review. Child Abuse Negl. 2000;24:129-140.

29. Duggan A, Windham A, McFarlane $E$, et al. Hawaii's healthy start program of home visiting for at-risk families: evaluation of family identification, family engagement, and service delivery. Pediatrics. 2000; 105(1 Pt 3):250-259.

30. Glass N, Dearwater S, Campbell J. Intimate partner violence screening and intervention: data from eleven Pennsylvania and California community hospital emergency departments. J Emerg Nurs. 2001;27: 141-149.

31. McFarlane J, Christoffel K, Bateman L, Miller V, Bullock L. Assessing for abuse: self-report versus nurse interview. Public Health Nurs. 1991;8:245-250.

32. Olds DL, Eckenrode J, Henderson CR Jr, et al. Long-term effects of home visitation on maternal life course and child abuse and neglect. Fifteen-year follow-up of a randomized trial. JAMA. 1997;278:637-643.
33. Eckenrode J, Ganzel B, Henderson CR Jr, et al. Preventing child abuse and neglect with a program of nurse home visitation: the limiting effects of domestic violence. JAMA. 2000;284:1385-1391.

34. McFarlane J, Soeken K, Wiist W. An evaluation of interventions to decrease intimate partner violence to pregnant women. Public Health Nurs. 2000;17:443-451.

35. Parker B, McFarlane J, Soeken K, Silva C, Reel S. Testing an intervention to prevent further abuse to pregnant women. Res Nurs Health. 1999;22:59-66.

36. Reid B, Long A. Suspected child abuse: communicating with a child and her mother. J Pediatr Nurs. 2002;17:229-35.

37. Sachs CJ, Koziol-McLain J, Glass N, Webster D, Campbell J. A population-based survey assessing support for mandatory domestic violence reporting by health care personnel. Women Health. 2002;35: 121-133.

38. American Academy of Pediatrics Committee on Child Abuse and Neglect. Guidelines for the evaluation of sexual abuse of children. Pediatrics. 1991:87:254-260.

39. American Medical Association Diagnostic and Treatment Guidelines on Child Sexual Abuse. Arch Fam Med. 1993;2:19-27.

40. American Medical Association Diagnostic and Treatment Guidelines on Child Physical Abuse and Neglect. Arch Fam Med. 1992;1:187-197.

41. MacMillan HL, Canadian Task Force on Preventive Health Care. Preventive health care, 2000 update: prevention of child maltreatment CMAJ. 2000;163:1451-1458.

42. CDC Community Guide to Preventive Services. First Reports Evaluating the Effectiveness of Strategies for Preventing Violence: Early Childhood Home Visitation and Firearms Laws. MMWR Recommendations and Reports - October 3, 2003.

43. Guidelines for Women's Health Care, 2nd ed. Washington, DC: American College of Obstetricians and Gynecologists; 2002.

44. American Medical Association Policy Statement on Family and Intimate Partner Violence H-515.965. Available at: http://www.amaassn.org/apps/pf_online/pf_online. Accessed November 28, 2003.

45. AMA Council on Scientific Affairs. Diagnostic and Treatment Guidelines on Elder Abuse and Neglect; 1992.

46. Wathen CN, MacMillan HL, and the Canadian Task Force on Preventive Health Care. Prevention of violence against women: recommendation Statement from the Canadian Task Force on Preventive Health Care. CMAJ. 2003;169:582-584.

47. American Academy of Family Physicians. Family Violence and Abuse. Available at: http://www.aafp.org/x16506.xml. Accessed December 11, 2003.

48. Hyman A, Schillinger D, Lo B. Laws mandating reporting of domestic violence. Do they promote patient well-being? JAMA. 1995;273: 1781-1787.

49. Lachs MS, Pillemer K. Abuse and neglect of elderly persons. N Engl J Med. 1995;332:437-443. 